\title{
Gabriela Mistral recrea a Caperucita, Blanca Nieve, Cenicienta y Bella Durmiente: una poética americanista y feminista basada en la ética del cuidado*
}

\author{
Gabriela Mistral recreates Little Red Riding Hood, Snow White, \\ Cinderella, and Sleeping Beauty: an Americanist and feminist \\ poetic based on care ethics
}

Andrea Casals Hill**

\section{RESUMEN}

En este artículo desarrollo una lectura comparada entre las ver-

Palabras clave: siones poéticas realizadas por Gabriela Mistral entre los años 1924 y 1928 de cuatro cuentos clásicos (Caperucita, Blanca Nieve, Cenicienta y Bella Durmiente), reeditadas recientemente por la editorial Amanuta. Con un aparato crítico articulado desde la ética del cuidado, propongo una lectura crítica que acompaña Mistral, ética del cuidado, cuentos de hadas, libro ilustrado, estereotipos.

la mirada atenta de Mistral de los derechos de niños y niñas y el estatus de la mujer latinoamericana en la década de 1920 y de cómo, en las ilustraciones recientes se refuerza el sesgo de las representaciones populares y eurocéntricas.

\begin{abstract}
This article develops a comparative analysis concerning Gabriela Mistral's poetic version of Little Red Riding Hood, Snow White, Cinderella, and Sleeping Beauty written between 1924 and 1928, recently re-edited by Amanuta. Drawing criteria from the ethics of care, we propose a critical reading guided by Mistral's avantgarde view of children's rights and Latin American women's status in the 1920s decade.
\end{abstract}

Keywords: Mistral, Ethics of care, Fairy tales, Picture books, Stereotypes.

\footnotetext{
* $\quad$ Este artículo forma parte del proyecto de investigación posdoctoral Fondecyt n ${ }^{\circ}$ 3170134 "Conciencia ambiental en la literatura infantil ilustrada chilena del nuevo milenio", donde la autora de este artículo es la investigadora responsable.

** Chilena. Doctora en Literatura. Profesora asistente adjunto en la Facultad de Letras de la Universidad Católica de Chile, Santiago, Chile. acasals@uc.cl
} 


\section{Introducción}

A comienzos del siglo XX en Chile, el "ideal" de la familia nuclear madre, padre, hijos- era tan solo una ilusión. Hoy esa idea de familia es cuestionada, pero al igual que entonces, son mayoritariamente las madres quienes se hacen cargo de la crianza. En Chile, cerca de un $48 \%$ de niños y niñas no vive con ambos padres, y el $77 \%$ de los hogares monoparentales está a cargo de la madre, lo que repercute en mayores índices de pobreza infantil debido, entre otros factores, a los menores ingresos que reciben las mujeres por su trabajo en comparación con los hombres (Ministerio de Desarrollo Social y Familia s/p). En el ensayo Madres y huachos (2001) la antropóloga Sonia Montecino ofrece una explicación para esta situación y sostiene que desde la colonia el abandono del hogar por parte del padre fue una práctica nacional, dejando a la madre sola con el peso de la mantención de la casa y la crianza de hijos e hijas (citada en Sepúlveda 63). Se estima que a comienzos del siglo pasado, "sobre todo en los distritos pobres, casi los dos tercios de los nacidos constituían casos de niños 'huachos"' (Salazar 22), lo que implicó que el bienestar de niñas y niños estuviera en la agenda pública ya en las primeras décadas del 1900 (Sepúlveda 63).

Esta realidad no fue ajena para Gabriela Mistral, como lo demuestra su creación poética y muchos de sus escritos en prosa. El legado mistraliano incluye una enorme cantidad de prosa donde la poeta se expresa en torno a estas materias. A saber, entre los escritos que figuran en el libro Magisterio y niño (una selección de prosa de Mistral publicada por Roque E. Scarpa), Mistral elabora una declaración de "Los derechos de los niños"1 mucho antes que la Declaración de las Naciones Unidas ${ }^{2}$. Establecer esta distancia temporal entre la declaración de la ONU y la declaración mistraliana no es un juego retórico: por medio de este gesto político, Mistral está ampliando el círculo del cuidado desde lo privado a lo público. Desde la "ética del cuidado", es ético preocuparse y movi-

1 Ponencia escrita en París en 1927 y presentada en Buenos Aires en 1928 en la Primera Convención Internacional de Maestros.

2 La resolución de la Asamblea General de las Naciones Unidas por los derechos de los niños es de 1959; en 1989 la Asamblea General la adoptó; entró en vigencia recién en 1990. 
lizarse por el cuidado de otro ser - humano o más que humano ${ }^{3}-\mathrm{a}$ pesar de que a estos aún no se les haya reconocido un derecho (Curtin, “Toward an ecological..." 65). En su declaración, el juicio de Mistral es tan radical, que ella considera que el cuidado de los niños es el único lujo que una sociedad honesta debiera permitirse. A la situación de niñas y niños huachos que refiere Montecino, Mistral propone el "Derecho del niño sudamericano a nacer bajo legislación decorosa ... [donde] el Estado acepta al hijo de la madre desgraciada como un miembro más ..." (65) ${ }^{4}$. Entiendo la imagen de la "madre desgraciada" como la madre del huacho que cría sola y debe trabajar para alimentarlo. Como observan Figueroa, Silva y Vargas (2000) en su estudio referido al pensamiento social de Gabriela Mistral, ser madre en esas condiciones "era también una de las peores afrentas que podía sufrir una mujer, ya que recibía a cambio el rechazo social y jurídico: su hijo siempre sería un 'huacho', alguien marcado por el deshonor" (s/n). En el poema "La madre triste", que entiendo como sinónimo de la madre desgraciada, la hablante le canta a su bebé - y se canta a sí misma - destacando su propio cansancio: "Duerme, duerme, dueño mío / sin zozobra, sin temor, / aunque no se duerma mi alma, / aunque no descanse yo" (105), cansancio que podemos atribuir a la situación social descrita.

Entre otros derechos, Mistral destaca el derecho a la educación secundaria y superior para así dotar al ciudadano de criterio (65). A comienzos de la década del 1920 Mistral residió en México por su compromiso con la educación, invitada por José Vasconcelos para contribuir al proyecto educativo de Álvaro Obregón, quien gobernó entre 1920 y 1924 después de años de guerra civil. Este proyecto confiaba en la capacidad de artistas, poetas y educadores para promover la construcción de un ideario nacional que valorara los pueblos indígenas de México (Sepúlveda 65). Durante su estadía, Mistral compiló una colección de textos orientados a lectoras trabajadoras jóvenes que asistían a una escuela vespertina. La colección fue publicada en 1924 con el títu-

3 El concepto de más que humano (more-than-human world) fue elaborado por David Abram en el texto The spell of the sensuous (1996), para incluir, o más bien no excluir a los seres no humanos, enfatizando que el mundo más que humano es tanto más amplio que la experiencia humana.

4 En Chile, recién en 1998 se promulgó la Ley de Filiación que asegura los mismos derechos ante la ley para hijos nacidos dentro o fuera de un matrimonio. Con ello se puso fin a la discriminación que distinguía entre hijos legítimos, ilegítimos y naturales desde 1855 . 
lo Lecturas para mujeres (1924) e incluye narrativa de ficción, poesía y ensayos de una gran variedad de autores, incluyendo su propia versión poética de "La Caperucita Roja".

En la introducción de Lecturas... Mistral declara que los libros del sistema escolar tienden a enfocarse en los intereses de los niños, pero no atraen a las niñas. A pesar de que hoy en día este juicio nos puede parecer discriminador, no obstante, si leemos con atención y en contexto, entenderemos que esta compilación es feminista y liberadora. El solo hecho de que en 1924 Mistral pusiera las necesidades e intereses de niñas y mujeres en el primer plano, cuando estas apenas recibían educación formal y ni siquiera tenían derecho a voto, constituye subversión ${ }^{5}$. No obstante, la gran transgresión que ejerce Mistral con esta antología radica en la lectora que ella imagina y construye a través de las lecturas escogidas. Mistral proyecta una colección con la cual las jóvenes trabajadoras puedan identificarse, que empodere y dignifique a quien lee, y procure "una formación ciudadana de sus lectoras" (Mayne-Nicholls "Mistral ilustrada" 22). Los textos seleccionados por Mistral versan en torno a la pobreza, desprotección, madres solteras, y el valor de los alimentos latinoamericanos, como forma de subsistencia para las comunidades indígenas y campesinas (Sepúlveda 66), lo que facilitaría la identificación de las lectoras que Mistral proyecta. Su apropiación americanista de estos cuentos centroeuropeos es coherente con el poema "Andersen", donde la poeta se imagina en un diálogo de igual a igual con el escritor danés: "Me habrías dicho: ahora / cuenta los tuyos [...] / Yo te habría ido contando al quechua, al mexica, al chileno... (328), valorando la tradición oral andina y destacando su propia capacidad de contadora de cuentos.

En este ensayo me propongo desarrollar una lectura atenta y comparada de las apropiaciones poéticas que hace Mistral de cuatro cuentos de hadas centroeuropeos, con el fin de demostrar la coherencia de Mistral con su visión feminista y latinoamericanista, así como su postura frente a la protección de la infancia. Leo a Mistral desde la recien-

5 En Chile la mujer obtuvo el derecho a voto en 1934, pero votó por presidente por primera vez recién en 1952. En México las mujeres obtuvieron el derecho a voto en 1953, pero votaron a nivel nacional por primera vez en 1955. 
te publicación en formato ilustrado que hiciera editorial Amanuta ${ }^{6}$ : la comparación entre los versos mistralianos y las ilustraciones contemporáneas que los acompañan me permiten argumentar que aún hoy, a 75 años del Nobel, como sociedad seguimos leyendo a Mistral superficialmente, obviando su visión crítica de la sociedad latinoamericana de inicios del siglo XX.

\section{Reescritura mistraliana}

Las versiones poéticas de Mistral de cuatro cuentos de hadas centroeuropeos fueron escritos entre 1924 y 1928, y publicados en diferentes periódicos latinoamericanos. De acuerdo con Manuel Peña, estas apropiaciones de Mistral se basan en las versiones escritas por Charles Perrault (1626-1703) para Caperucita Roja, La Bella Durmiente y La Cenicienta, y para Blanca Nieve en la versión de 1812 de los hermanos Grimm (Jacob Grimm 1785-1863; Wilhem Grimm 1786-1859) (Peña $32)^{7}$. Entre 2012 y 2014 editorial Amanuta publicó los versos mistralianos para estos cuentos en cuatro libros independientes, cada uno ilustrado por un/a artista de renombre en el ámbito de la ilustración contemporánea. Al presentar estas nuevas ediciones, Peña destaca la cualidad lírica de los versos mistralianos, asegurando que los versos octosilábicos (para tres de los cuatro cuentos) son especialmente apropiados para tales cuentos, dado que reflejan trazos de oralidad distintivos de su origen. Así, Mistral inscribe su obra en lo que, siguiendo a Pérez López ${ }^{8}$, considero el "flujo del compostaje cultural". Es decir, una obra que muestra claras señas de reciclaje de otra obra precedente que se entreteje con fragmentos intertextuales propios y ajenos, dando origen a una nueva creación. Esta obra escrita sobre la base de diversas capas de objetos culturales anteriores, a la vez, queda abierta - o dis-

6 Destaco que estos cuatro libros publicados por editorial Amanuta son obras galardonadas a nivel nacional e internacional entre los que se cuentan los premios Libro más Bello 2014 (Comisión Alemana para la Unesco y Fundación Alemana de las Artes Gráficas), Premio a la Edición, Municipalidad de Santiago 2013, y la mención honrosa en la categoría Nuevos Horizontes de la Feria del Libro de Bologna.

7 Por extensión, no me detengo en resumir los cuentos; asumo que los lectores estarán familiarizados con sus versiones clásicas, así como con las versiones cinematográficas de Disney.

8 Para profundizar en este concepto, ver: Pérez López, María Ángeles. "La autotextualidad en Nicanor Parra: Acotar/Agotar/Reciclar." Anales de Literatura Chilena, no.4, 2003, pp. 165-75. 
ponible en la compostera - para ser tomada y reciclada nuevamente por artistas posteriores, circulando nuevamente en el flujo del compostaje cultural ${ }^{9}$.

En esta lectura de las apropiaciones mistralianas destacaré el compromiso ético de Mistral por escribir para lectoras jóvenes, trabajadoras, invisibilizadas, abandonadas y por tanto abusadas por la sociedad latinoamericana de comienzos del siglo XX. Es importante destacar que Mistral no normaliza el abuso. En su estudio acerca del cuento de Hansel y Gretel, Jack Zipes sostiene que sus receptores también son abusados por las subsiguientes versiones que fueron corrigiendo los hermanos Grimm debido a que estos textos normalizan el abuso: "Los niños como lectores y receptores auditivos son abusados por medio de reescrituras del texto y las transformaciones de los Grimm y las interpretaciones de los académicos que normalizan el abuso en el nombre del orden simbólico del padre"10 (41). En el caso de Hansel y Gretel, una vez que se liberan por sus propios medios de la bruja y se quedan con su tesoro, ellos vuelven al padre y le entregan el tesoro, como si no importara el abandono original. En el marco del cuento clásico tradicional, las protagonistas de Mistral despliegan agencia a pesar de las circunstancias abusivas que Mistral critica; de este modo, al promover la identificación con estas protagonistas independientes Mistral dignifica y empodera a sus lectoras sin normalizar el abuso.

\subsection{La Caperucita Roja}

La Caperucita Roja de Mistral fue publicada originalmente en 1924 en Ternura. A diferencia de los otros tres poemas, este está escrito en alejandrinos. La apropiación de Mistral es consistente con la escritura de Perrault ${ }^{11}, \mathrm{y}$ al igual que en la versión de este, no hay un final feliz. La ilustradora para la edición de Amanuta (2014) fue la artista chilena Paloma Valdivia, quien trabaja con colores saturados y líneas geomé-

9 Para profundizar en este concepto, ver Casals Hill, Andrea. "Violeta Parra en el flujo del compostaje cultural" (2017).

10 En el original: "Children as readers and listeners are abused through scripting of the text, its transformations by the Grimms, and interpretations by scholars that rationalize child abuse in the name of the symbolic order of the father"(41). La traducción es mía.

11 Leo a Perrault en Cuentos de hadas. Editorial Lumen, 1983. 
tricas. La abstracción de su estilo moderno y simple deja espacio para la interpretación de las lectoras ${ }^{12}$.

La Caperucita de Mistral es una niña con agencia que destaca por su corazón generoso. Entiendo por agencia la capacidad de tomar decisiones propias y de actuar con autonomía, y vinculo la valoración que hace Mistral del corazón generoso con la descripción que propone Carol Gilligan de la ética del cuidado, la cual "dirige nuestra atención a la necesidad de respuesta en las relaciones ... y a los costos de perder la conexión con uno mismo y con otros"13 (s/n); así, la ética del cuidado, supone que el ser humano es inherentemente relacional, empático y orientado a la cooperación.

Si la Caperucita de Perrault emprende camino por mandato de la mamá, la niña de Mistral lo hace por iniciativa propia: sabiendo que la abuela "sufre de extraño mal" (4), "va cruzando el bosque con pasito audaz" (6). No obstante, la autonomía de la Caperucita mistraliana discrepa de la ilustración de Valdivia que incluye a la madre despidiendo a la niña desde la puerta, como se observa en la Ilustración $1^{14}$.

Si Perrault introduce a Caperucita como la niña más bonita del pueblo (Perrault 9), Mistral destaca que su corazón es "tierno como un panal" (Caperucita... 4) y "cándida como los lirios blancos" (8). Siguiendo a Mistral en Los motivos de San Francisco (2008), "El hermano lirio es blanco, no por soberbia, sino para muestra de la blancura. Sin él, y sin la nieve que suele bajar tardíamente, los ojos se olvidarán de ella" (51). En esta lógica, la entrega y el riesgo que corre la Caperucita en su visita a la abuela "en el poblado próximo" (4) son testimonio, como el lirio blanco, de una ética del cuidado del otro. No obstante, la comparación también augura la muerte temprana de la niña; Mistral, en Los motivos... explica: "Es tan perfecto [el lirio] como si estuviese hecho para la eternidad y dura lo que una palabra en el viento" (51). Desde esta perspectiva, la comparación anticipa que la Caperucita, como el lirio,

12 Aunque la gramática castellana nos indica usar el masculino como neutro, y sin ánimo de excluir, en este ensayo utilizaré el femenino "lectora" y "lectoras" por coherencia con la vocación mistraliana y sus Lecturas para mujeres.

13 En el original: "directs our attention to the need for responsiveness in relationships ... and to the costs of losing connection with oneself and others". La traducción es mía.

14 Agradecemos a Editorial Amanuta por permitirnos reproducir esta y todas las ilustraciones incluidas en este artículo con fines académicos. 
no tendrán una larga vida, más esta tendría un sentido testimonial. Del mismo modo, comparando a la niña con el lirio, Mistral establece una significativa distancia entre la pureza de la niña y el lobo seductor.

Al igual que en el relato de Perrault, sin titubear y sin prejuicio, la Caperucita de Mistral le cuenta al lobo sus planes, pero a diferencia de Perrault, Mistral excluye la conversación acerca de qué camino tomar. A continuación, Mistral cuenta que la niña se deja encantar por las mariposas, frutos y flores que recolecta, olvidando completamente el encuentro con el "Traidor" (Caperucita... 10). Observamos la oposición entre la imagen de inocencia de la niña que juega en el bosque y el lobo alevoso. Sin embargo, a pesar de la insistencia en la inocencia de la niña, Mistral no limita su agencia; recordemos que ella inició su viaje con autonomía, y se apropia del camino no solo como una vía para llegar de un punto a otro, sino que lo utiliza como espacio de juego; es decir, Caperucita "sobrepasa los límites fijados por los adultos" (MayneNicholls "Espacios tomados" 82). Al evitar la indicación maliciosa que le da el lobo de Perrault a Caperucita acerca de qué camino debe tomar, Mistral deja espacio para que la niña elija libremente la ruta a seguir, a la vez que no deja espacio para interpretar que la niña andaba por mal camino. Mistral describe cómo la niña se apropia del camino y dice que Caperucita está "discurriendo encantada" mientras avanza por el bosque (10).

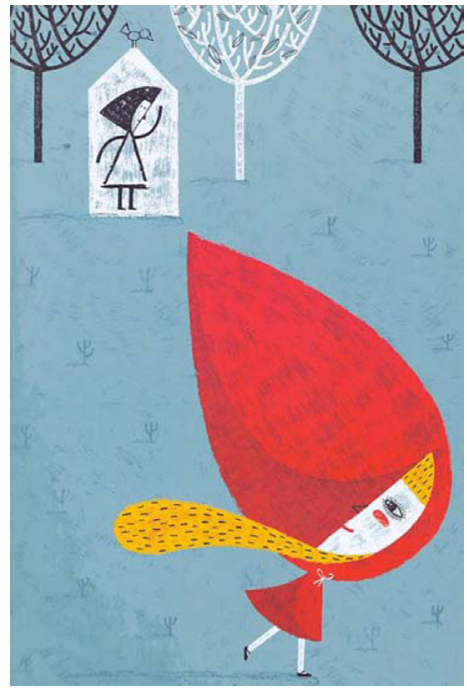

Ilustración 1. P. Valdivia, 2014, p. 5.

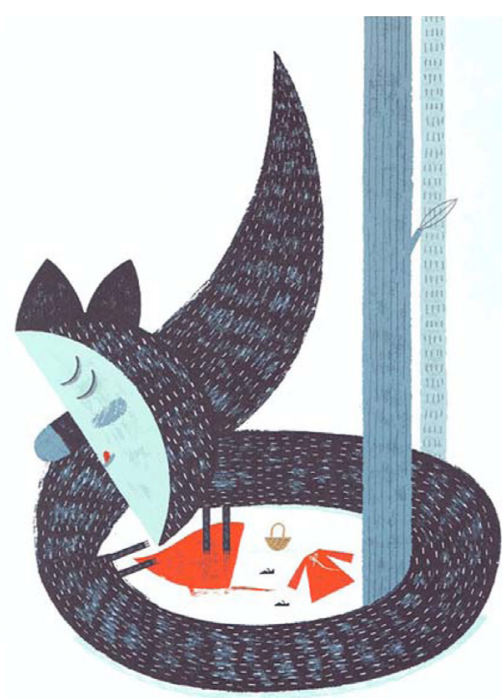

Ilustración 2. P. Valdivia, 2014, p. 27. 
Tras su llegada a la casa de la abuela, Mistral insiste en el uso de adjetivos descriptivos negativos para referirse al lobo: "El fabuloso de blanqueados dientes ... el Traidor" (12), donde fabuloso puede significar alguien fantástico, pero también una persona con la capacidad de fantasear y fabular cuentos engañosos. La imagen de los dientes blanqueados, o falsamente blancos, remite al refrán "Aunque el lobo se vista de oveja, lobo queda"; el embustero. Así, al igual que en el texto de Perrault, cuando la niña llega a la casa de la abuela este ya ha devorado a la anciana y se ha puesto sus ropas. Si bien la Caperucita de Mistral no logra reconocer el engaño cuando escucha la voz ronca del lobo, ella se ofrece a sí misma una explicación: “Pero la abuelita está enferma, / la niña ingenua explica" (16), demostrando agencia a través de su capacidad para sacar sus propias conclusiones, a pesar del error. A continuación, en el popular diálogo entre el lobo y la niña, Mistral vuelve a destacar las características siniestras del lobo, con descripciones tales como "orejas monstruosas" y "el velludo engañoso" (20).

En la penúltima estrofa Mistral indica: "El cuerpecito tierno le dilata los ojos [al lobo]. / El terror en la niña los dilata también” (22). El contraste entre estos dos versos marca el momento climático del poema; la excitación del lobo es opuesta al temor de la víctima. Cuando el lobo mistraliano se ríe, sus dientes blanqueados destellan con "terrible fulgor" (24), figurando al arquetipo del Don Juan. La estrofa final describe el crimen brutal donde el cuerpecito de la niña ya no es tierno sino que tembloroso:

Ha arrollado la bestia, bajo sus pelos ásperos,

el cuerpecito trémulo, suave como un vellón;

y ha molido las carnes, y ha molido los huesos,

y ha exprimido como una cereza el corazón... (26)

En su relato, Perrault simplemente declara que el lobo devoró a la niña; Mistral, sin embargo, se detiene y describe la brutalidad y sensualidad del crimen. El lobo disfruta al comerse a la niña; el lobo muele las carnes y huesos de la niña y le exprime "como una cereza el corazón" (26), evocando una violación, no solo en el disfrute del lobo, sino también al exprimirle la vida a Caperucita.

A pesar de que Mistral nunca reporta que la niña se haya desvestido, como sí sucede en el relato de Perrault, nuevamente omitiendo 
cualquier indicio que pueda inducir a culpar a la víctima por dónde andaba o cómo vestía ${ }^{15}$, en la ilustración de Valdivia el lobo figura como una enorme serpiente o dragón que encierra los restos de la niña y su ropa (ver Ilustración 2). El lobo de Valdivia se muestra sonriente, con los ojos cerrados, relamiéndose los bigotes, saboreando su ingesta. La imagen carnal que figura tanto en Mistral como en Valdivia, destaca el desequilibrio de las fuerzas en juego, dejando poco espacio para un juicio ambiguo: el lobo - el adulto- es un abusador. Siguiendo a Zipes, si bien en los versos de Mistral el crimen es brutal, su relato tampoco deja espacio para abusar de las lectoras, pues la condena de Mistral mediante la marcada oposición entre la niña inocente y generosa y el lobo-adulto violador es clara: culpable es el lobo y no Caperucita.

\subsection{Blanca Nieve en la casa de los enanos}

El poema de Mistral para el relato de Blanca Nieve es solo un fragmento del escrito de 1812 por los hermanos Grimm. Mistral se concentra en la llegada de la niña a la casa de los enanos. El poema de Mistral fue publicado por primera vez en el periódico colombiano El Espectador de Bogotá en 1925. Blanca Nieve de Mistral está escrito en patrones rítmicos siguiendo la regla de tres que nos recuerda el cuento de Ricitos de Oros, otra niña en busca de un hogar.

Originalmente -si se puede hablar de original cuando hablamos de tradición oral- en la versión de 1837 de Robert Southey (17741843), Ricitos de Oro era una anciana que entraba en la casa de tres osos solteros. Al igual que la Blanca Nieve de Mistral, al llegar a la casa de los duendes la anciana de Southey solo come del plato más pequeño y duerme en la cama más chica. Asimismo, la niña de Mistral anda en puntillas por la casa, temerosa de tomar la comida (11). Ocupar el mínimo espacio, notarse lo menos posible, dejar el mínimo rastro son gestos que evocan la borradura, marginalidad y la indiferencia con los niños, mujeres y ancianos (sin profundizar en el hecho de que Southey explícitamente enuncia que a nadie le importó el destino de la anciana una vez que ella salta por la ventana; implicando que, si no vemos la pobreza que ella simboliza, fácilmente podemos ignorarla). No obs-

15 En 2018, a casi 100 años de la apropiación poética de Mistral, la intervención callejera y colectiva de Las Tesis, "Un violador en tu camino", deja muy en claro en su refrán que "la culpa no era mía ni cómo andaba ni cómo vestía". 
tante, la mirada, la capacidad de ver al otro y notar su aflicción es central en la ética del cuidado, y esta se manifiesta en el poema mistraliano. Siguiendo a Nel Noddings, entiendo la ética del cuidado como la capacidad de dejarse conmover por la situación de otro ser vivo que sufre; donde conmoverse implica no solo notar este sufrimiento, sino que movilizarse para aliviarlo: "una vez detectada una necesidad expresada, la cuidadora 'siente con' el ser cuidado y experimenta desplazamiento motivacional; ... [y] responde positivamente a la necesidad... " (53a) ${ }^{16}$. Es decir, la ética del cuidado cristaliza en esa capacidad de respuesta - responsiveness - que propone Galligan.

En la primera ilustración en la edición de Amanuta a cargo de Carles Ballesteros, Blanca... es representada corriendo por el bosque hacia la casa de los duendes, sin embargo, Mistral nunca menciona una travesía por el bosque (ver Ilustración 3). La poeta canta que la niña corre cerro arriba: "sube, sube, / y golpea atribulada" (Blanca... 7), sugiriendo más bien una huida hacia los cerros de su "patria verdadera", el Valle del Elqui donde "se desarrolló [su] infancia" ("Algunos rasgos..." 41). La niña de Mistral está buscando un hogar y por sí sola encuentra su camino siguiendo una luz:

En lo alto de una loma

[donde] está encendida una casa,

y pestañea en la sombra

como una madre que llama. (4)

Tanto en este poema como en los nombres y metales de los duendes, y en la flora y fauna que menciona, observamos que Mistral cultiva la americanización del poema. Como señala Peña, "[l]a autora introduce mexicanismos con lo cual se apropia del personaje europeo y lo americaniza" (Peña, "Blanca...” 30). En particular, al ubicar la casa que con su luz llama a la niña desde "lo alto de una loma" (4), Mistral no solo ubica el cuento en los montes, sino que convoca el encuentro con la madre que la llama. En su declaración de derechos de los niños, para Mistral, crecer bajo la mirada vigilante de la madre es otro derecho (Magisterio... 24). Entiendo "vigilante" no como un control, sino desde

16 En el original: "on detecting an expressed need, the carer 'feels with' the cared for and experiences motivational displacement; ... [and] responds positively to the need..." La traducción es mía. 
la noción de vigilia; la madre vigilante sería aquella que está siempre atenta, despierta, como la hablante que canta en la canción de cuna "Apegado a mí" que no se quiere dormir para estar atenta a su bebé: "Yo que todo lo he perdido / ahora tiemblo hasta al dormir" (Ternura). Asimismo, en este cuento hecho poema la loma bien puede estar en los faldeos de la Cordillera de los Andes. Recordemos que para Mistral este cordón montañoso que cruza el continente de sur a norte, también es madre: "Cordillera de los Andes, / Madre mía, madre lejana [ ... ] corazón sacro y recóndito / que sin semblante nos mirara" ("Cordillera II" 45). Siguiendo a Grínor Rojo (1997), en Mistral la Cordillera de los Andes es la matriz - madre - común que hermana a "los pueblos de América" (266). De tal modo, podemos entender que Blanca Nieve encuentra su camino al hogar, y como veremos, también descubre una comunidad de hermanos.

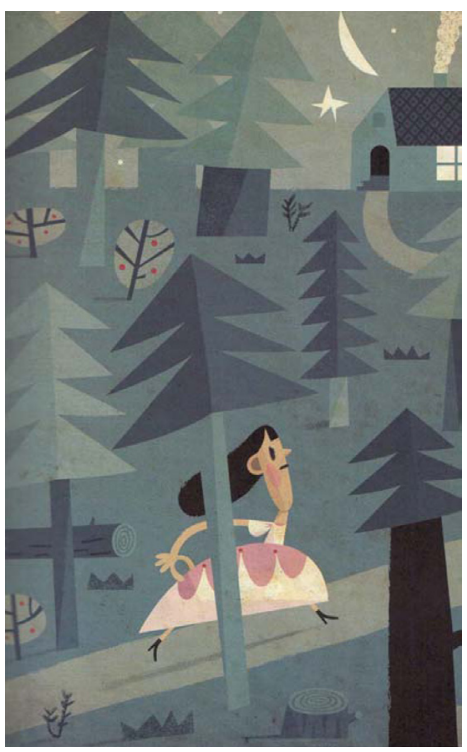

Ilustración 3. C. Ballesteros, 2014, p. 5.

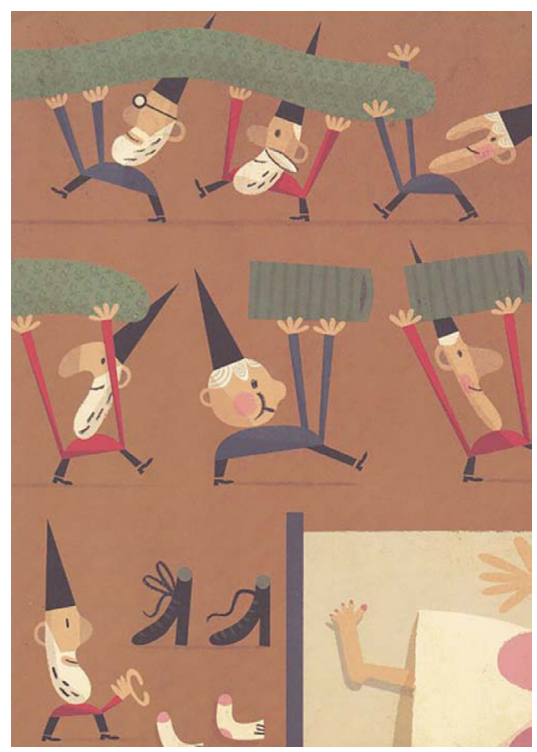

Ilustración 4. C. Ballesteros, 2014, p. 28.

En el fragmento que versifica Mistral, una vez que "los duendes de los metales" (29) han descubierto la presencia de la niña, luego de escucharla con un corazón abierto, conmovidos, le ofrecen un hogar. En su estudio sobre Poema de Chile, Soledad Falabella destaca que "el tema de 'la casa', surge a raíz de que el niño [que acompaña a la mamá fantasma en el recorrido por Chile] está cansado de "vagar". Manifiesta 
su deseo por tener un hogar, donde duerma sin miedo de viento, rayo y nevadas" (s/n). Igual que el niño indio de Poema de Chile, cansada de vagar, al llega a la casa en lo alto del cerro la niña se duerme, mas al reconocer su necesidad de un hogar, los duendes se movilizan - "responden" como dice Gilligan - reorganizando la casa para que Blanca Nieve esté cómoda. Esta conmoción es ilustrada imaginativamente por Ballesteros, con sus duendes moviendo muebles (ver la Ilustración 4). No obstante, a pesar de que los duendes mistralianos son claramente americanos, "Plata" y "Estaño Azul" son sus nombres (24), Ballesteros mantiene la estética del duende europeo, "con sus gorros puntiagudos, [y] sus barbas blancas" (Mayne-Nicholls "Mistral ilustrada" 38), lo que sin embargo, es consistente con los bosques de pinos europeos y la vestimenta de princesa con que Ballesteros ha ilustrado a la niña, ignorando por completo la americanización presente en los versos mistralianos.

Una vez que está cada cosa en su lugar, Mistral cuenta que los duendes "por fin la van durmiendo / con canción enamorada" (24). En ese proceso, ellos acogen a la niña dándole nombres tiernos tales como "olor a salvia mojada ... cuesta con almendros ... vertiente de la montaña" (23). Los duendes de Mistral no le piden nada a cambio, como el trabajo doméstico que explícitamente le piden a Blanca Nieve los duendes de Grimm y destaca la versión fílmica de Disney de 1937. Ellos simplemente ofrecen su protección contra "los monstruos de la montaña" y "el lagarto volador" (27). En el poema de Mistral, escuchar con empatía suscita una respuesta generosa de parte de los duendes, quienes le ofrecen un hogar a la niña como el que la poeta describe en su declaración de derechos de los niños: “.. derecho a la casa, no solamente salubre, sino hermosa y completa; derecho al vestido y a la alimentación..." (62).

Por último, si escuchar las aflicciones de Blanca Nieve con un corazón compasivo es la clave en la obra mistraliana, en su apropiación de la Cenicienta será determinante la capacidad de ver más allá de las apariencias.

\subsection{La Cenicienta}

La Cenicienta de Mistral fue publicada por primera vez en El Tiempo de Bogotá, Colombia, en 1926. Para la edición de Amanuta (2014), la 
ilustradora fue Bernardita Ojeda, una colaboradora constante de la editorial. Algunas de las ilustraciones de Ojeda muestran de manera lúcida el abuso al que está sometida la niña. Sin embargo, la interpretación de Ojeda no alcanza a dar cuenta de la apropiación andina que desarrolla Mistral en el poema.

En la Ilustración 5 se puede observar a Cenicienta escondida detrás de una puerta. Su cabeza apenas emerge de la hoja blanca, como si se asomara por un ojal para ver qué sucede al otro lado de la doble hoja, en la sala de al lado; la niña es casi invisible. Sus hermanastras y madrastra ocupan todo el espacio en la hoja opuesta, donde la presencia de Cenicienta es apenas insinuada por las manos laboriosas que peinan y engalanan a las hermanastras. Las expresiones agresivas y despectivas de estas complementan la descripción mistraliana de las ogresas, contrastando con la marginalidad figurada de Cenicienta. Observo, sin embargo, que las ilustraciones no alcanzan a reflejar la descripción que hace Mistral de la niña desposeída. Mistral imagina que el traje diario de la niña es una túnica de saya, un sayal penitente, cubierto de hollín (4), mientras que aun cuando está manchado, la ilustración representa a Cenicienta con su traje celeste y mangas infladas, que evoca a las princesas con vestido de organza de Disney (1950), eclipsando el abuso que denuncia Mistral.

La saya es la túnica que usan los ascetas o los penitentes en cuaresma. Para Mistral, el sayal tiene un valor profundo. En Los motivos de San Francisco, Mistral dedica una viñeta al sayal del santo y dice: “¿Por qué hiciste tu sayal de ese color de castaña, Francisco? Tal vez te lo dieron las espigas quemadas. Ellas disimulan la harina blanquísima que las hincha $\left[{ }^{17} \ldots\right]$. Así tú disimulas tu santidad. [...] O tal vez lo elegiste por ser el color de la tierra desnuda, el más desdeñado; pero que es bueno para el servicio cotidiano" (Los motivos... 42). De tal modo, podemos interpretar los primeros cuatro versos como una valorización mistraliana de la niña que viste una "penitente saya" (4), dedicada al servicio cotidiano; esa niña amerindia, morena y trabajadora a quien Mistral dedica las Lecturas para mujeres.

17 Sospecho un anuncio de mestizaje en estas palabras; como en el poema al "Pan": "Dejaron un pan en la mesa, / mitad quemado, mitad blanco" (225-226). 

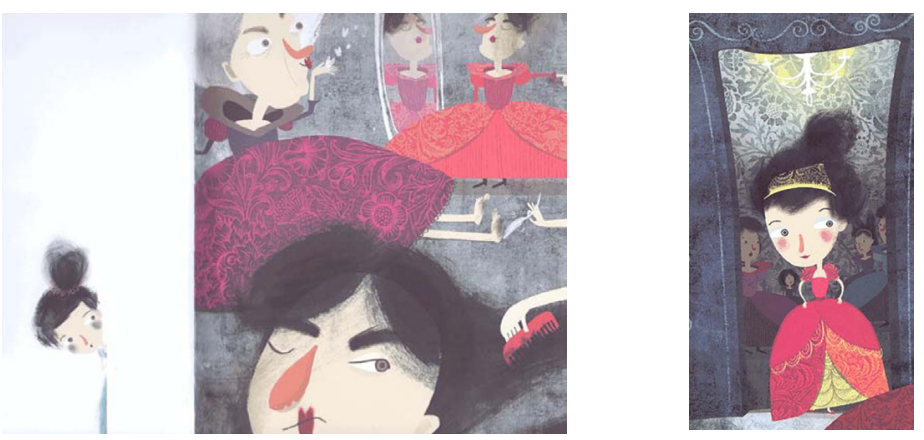

Ilustración 5. B. Ojeda, 2014, pp. 6-7. Ilustración 6. B. Ojeda, 2014, p. 15.

Una vez que las tres ogresas se han ido al baile, Mistral describe la soledad de Cenicienta:

¡Ay!, qué callada la noche

para oírse el corazón,

¡la Cenicienta que llora

apegadita al fogón! (10)

Cuando aparece el hada, ella le pide a Cenicienta que le abra su corazón (12). Y la niña le responde:

-Soy la hija del Tizón;

Y la ceniza me cubre

hasta el mismo corazón. (13)

Un tizón es un leño a medio quemar, a medio consumir, como la misma infancia de la niña agotada por el trabajo forzado al que está sometida. Ante la declaración de la niña, el hada se pone en movimiento, cristalizando la ética mistraliana. Si en el poema "Piececitos" (177-178) la poeta se indigna porque nadie se inmuta con el frío que azula los pies descalzos del niño, en su apropiación del cuento clásico, Mistral muestra cómo el reconocimiento del sufrimiento de la niña moviliza al hada, cristalizándolo en ética del cuidado.

Al igual que en la versión de Perrault, Mistral opta por desplegar dos bailes. De tal modo, la primera noche Cenicienta recibe los dones del hada Esplendor, y la segunda noche la viste Resplandor; cada una fabricándole un atuendo diferente. Luego de mirar a la niña con atención, Esplendor viste a la niña con un velo dorado y un vestido color amaranto y carmesí (ver Ilustración 6). 
La va mirando, mirando

y el mirarla es cubrir

su cuerpo de velo de oro, amaranto y carmesí. (13)

El amaranto es un cereal nativo de los Andes que fue fundamental en la alimentación de las culturas prehispánicas. Por su parte, originalmente el carmesí fue un color que se obtenía en Europa mediterránea a partir de un insecto (Kermes vermilio) que vive en ciertos arbustos (Quercus coccifera); sin embargo, una vez que los europeos llegaron a América, para la producción del color carmín se comenzó a utilizar la Cochinilla americana que se cría sobre los nopales - emblemáticos en la cultura azteca - ya que produce un tinte más intenso. De tal forma, sugiero que en la confección del vestido para el primer baile, Mistral revela su valorización de la cultura andina y los alimentos nativos.

Para la segunda noche el hada Resplandor viste a la niña con un manto azul estrellado. Haciendo una yuxtaposición entre ambos trajes, propongo que Mistral construye la imagen de la Virgen de Guadalupe, tal como se le apareció al niño indígena en 1531 y quedó estampada en un ayate (como el "sayal penitente" de la Cenicienta) ${ }^{18}$. Como se observa en la iconografía de la Virgen de Guadalupe, ella figura ataviada con vestido rojo, capa azul estrellada y rayos dorados sobre su cabeza, como el "velo de oro" de la Encenizada mistraliana (13).

No obstante lo anterior, la americanización del cuento por parte de Mistral va más allá. Cuando la niña y el príncipe se unen, Mistral dice que esa "misma mañana / desposó el príncipe Sol / a María Cenicienta" (28). Recordemos que las culturas andinas ${ }^{19}$ adoraban al Sol y Mistral bien lo sabe. El poema "Sol del trópico" (publicado en Tala en 1938) es un himno; una larga letanía que reúne a los diversos pueblos americanos en torno al Sol, incluyendo incas, mayas, aimaras y quichés. Referirse al príncipe de este cuento como el príncipe Sol subvierte el

18 La creencia en la Virgen de Guadalupe es central en la identidad cultural mexicana. La Virgen de Guadalupe se apareció cuatro veces ante el joven indígena Juan Diego en 1531. Su imagen quedó estampada en su tilma o ayate cuando el joven se presentó ante el obispo para informarle de la aparición. Esta imagen obtuvo la coronación canónica del papa León XIII en 1895.

19 Utilizo aquí el concepto de cultura andina como lo hace Magda Sepúlveda en Somos los andinos que fuimos para referir a la mega región cultural. 
cuento europeo, apropiándose de él en un acto de sincretismo. Yendo aún más lejos en su osadía, que en la estrofa final Mistral nombre a la niña María Cenicienta no solo reafirma la identificación con María de Guadalupe, sino que nombrar así a quien solo unos minutos antes era una encenizada, hija del Tizón, la sirvienta-esclava, huérfana, refuerza también la intención de permitir que las lectoras se identifiquen con la protagonista.

De acuerdo con el documental Marías, por Yosoyoho ${ }^{20}$, la mayoría de las jóvenes indígenas empleadas para hacer trabajo doméstico en Ciudad de México serían llamadas María por sus empleadores, ignorando sus nombres indígenas. Como sostiene Debra Dudek "la borradura del nombre constituye un significante de pérdida" $(366)^{21}$, lo que establece a la vez un abuso de poder. En este sentido sostengo que mediante la apropiación de este cuento de hadas Mistral está denunciando el trabajo infantil y la indolencia hacia las niñas trabajadoras indígenas, evidenciando la incapacidad de nuestra sociedad mestiza de reconocer a la culturas originarias, o ver su aflicción y mucho menos movilizarnos para defender sus derechos. Cuando Mistral llama a la niña "desnudita hija de Dios" (28), la poeta está bendiciendo, dignificando y empoderando a las lectoras y a todas la niñas abandonadas y maltratadas por la sociedad. En esta secuencia, Mistral invierte y feminiza el Evangelio: ya no es el Hijo amado, sino que invoca a una hija amada, estableciendo una comunidad entre todas las Marías, que se convierten en las bendecidas de las Bienaventuranzas.

\subsection{La Bella Durmiente}

El cuarto cuento clásico versificado por Mistral y editado por Amanuta (2012) es La Bella Durmiente, publicado en 1928, también en Colombia, en El Gráfico. La ilustradora para la edición fue Carmen Cardemil, ganadora de diversos premios por su trabajo en ilustración con las técnicas de collage y grattage. El uso de estas dos técnicas resuena con la apropiación y reciclaje cultural que compone Mistral en tanto construye sobre la base de variadas capas de intertextualidad, particularmente en este cuento.

20 Marías de Yosoyoho es accesible por Facebook: https://www.facebook.com/ watch/?v=860117457496417

21 En el original: "erasure of a name [is]a signifier of loss". La traducción es mía. 
Como presenté anteriormente, uno de los derechos de los niños expresados por Mistral es "el derecho a la madre a lo largo de su infancia, a su ojo vigilante" $(24)^{22}$, elemento que es clave en la Bella Durmiente mistraliana, aunque también está presente - o más bien ausente- en Blanca Nieve y Caperucita, ambas deambulando solas por el bosque. En la versión de Perrault, el rey y la reina andaban en su finca de recreo cuando su hija sufre el temido accidente. La ausencia del ojo vigilante de la madre se repite cuando todos duermen gracias a la magia del hada más joven ${ }^{23}$. En ese momento, en el relato de Perrault, la reina y el rey abandonan el palacio; en la versión de Mistral, solo el rey abandona a su familia. Es decir, como lo describe Montecino en Madres y huachos, este hogar también fue abandonado por el padre (citado en Sepúlveda 63).

Artísticamente Mistral enumera a todos los que se van quedando dormidos, y en un gesto de metaescritura, dice que incluso "se durmió la que lo cuenta" (22). Para rematar la escena del bosque también dormido, cuentan los versos mistralianos que después de 100 años, cuando venía por ahí Caperucita, evitando el bosque hechizado, esta hasta se santiguó (24).

Como he expuesto anteriormente, un aspecto recurrente en la reescritura mistraliana de estos cuentos - y con lo que se diferencia de los relatos de Perrault y los hermanos Grimm-, es la celebración del espíritu noble, por sobre cualquier belleza superficial, cuestión que se observa también en La Bella Durmiente.... Si las hadas de Perraut le otorgan a la niña el don de ser la persona más bella del mundo, las hadas de Mistral traen en sus "morrales" campesinos dones tales como armonía, felicidad, "el don de hacer danzar", "el don de hacerse amar", "volverse pájaro", “... atravesar / las montañas y los mundos" (8), otorgándole agencia a la niña, y a través de ella, a sus lectoras. Me detengo

22 A fin de asegurar el derecho de los niños a crecer junto a la madre, reconociendo la necesidad del trabajo remunerado y los nuevos horizontes que se abrían para las mujeres, Mistral agrega que el Estado debe procurar que las mujeres puedan trabajar desde la casa (64).

23 Siguiendo a Figueroa, Silva y Vargas en el Pensamiento social de Gabriela Mistral, Mistral distingue entre las madres burguesas y ricas que entregan la crianza de sus hijos a otras mujeres, y las mujeres que deben trabajar fuera del hogar justamente para mantenerlo; Mistral celebra la independencia económica de las mujeres trabajadoras, pero a la vez advierte los riesgos de que niños y niñas crezcan sin su mirada amorosa y atenta. 
aquí en el don de "hacer danzar" para recordar que en Mistral, la danza como "La ronda ... no apela solamente a un colectivo, a una voz plural, sino a una hermandad; para que exista, nadie puede quedar atrás" (Mayne-Nicholls "Espacios tomados" 171). En esta línea, los dones de las hadas mistralianas se extienden hacia la comunidad.

En la apropiación de Mistral, el hada más joven, aquella que neutraliza el embrujo, se llama Corazón, y es representada pequeñita por Cardemil, en contraste con el "hada, vieja fea, / con hocico de chacal" (10) que aparece tremenda, ocupando todo el espacio de la hoja cuando Corazón se le enfrenta. La técnica de Cardemil es sutil y etérea para Corazón, pero densa para el "Hada fea, turba fiestas, / rompedora de canción” (14), como recita Corazón.

La ilustración de Cardemil (Ilustración 7) representa la falta de equilibrio de fuerzas entre las dos hadas, lo que nos recuerda la batalla entre David y Goliat.

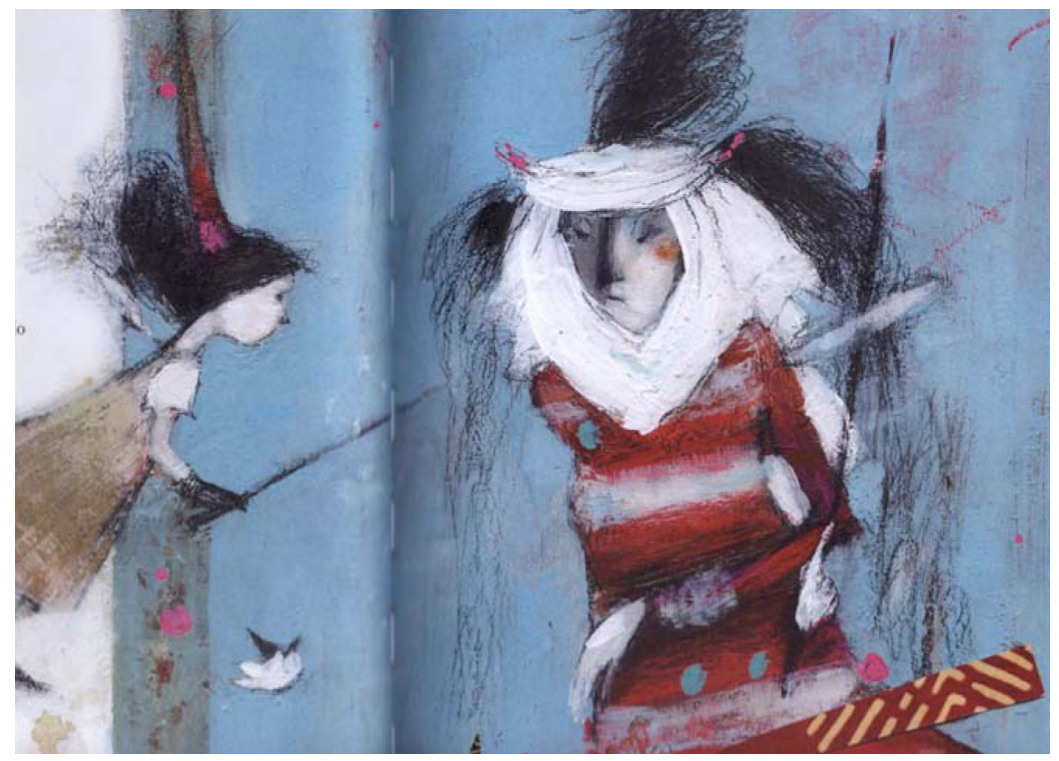

Ilustración 7. C. Cardemil, 2012, pp. 14-15.

Sin embargo, lo que parece dar la unidad a esta apropiación de La Bella... es otra figura bíblica: la interdependencia del bien y el mal, como el trigo y la cizaña. La alusión se repite a lo largo del poema. Mistral comienza por decir que el rey convidó "a las hadas, que reparten, / como harina, el bien y el mal” (6). En su entrada dramática, el hada que 
no fue invitada exclama: "me olvidaste como al Mal" (10). Y conforme crece la niña, Mistral cuenta que solo un huso quedó en palacio, pero este era invisible, "como suele serlo el mal" (18). Como sucede en la versión cinematográfica de Disney (1959), "[l]a princesa una mañana / en el techo oyó cantar, y siguió subiendo el canto" (20). En el desván encuentra una vieja que "hilaba en suave / lana blanca, el negro Mal" (20). En esta imagen no solo aparece nuevamente el contraste entre bien y mal, sino que la idea del engaño - como el lobo con dientes blanqueados, como el lobo vestido de oveja- en este poema, el mal se viste de lana blanca. Si bien la niña tuvo la agencia para encontrar el huso, en este poema quien demuestra mayor agencia es el hada Corazón. Ella logra mitigar la maldad del hechizo inicial, cambiando la sentencia de muerte por un letargo de cien años. Como en la versión de Perrault, el hada Corazón de Mistral se anticipa al despertar desolado de la durmiente, y "Para que cuando despierte / no se llene de terror, / [ordena] que se duerma el mundo todo / al callar su corazón..." (14). Así, la pequeña hada no solo muestra agencia tomando la iniciativa y cambiando las crueles circunstancias provocadas por el hechizo fatal, sino que se adelanta empáticamente cambiando las condiciones futuras de un despertar en soledad a uno cobijado por la comunidad que acompaña.

\section{Conclusión}

En esta lectura de la versión poética de cuatro cuentos de hadas clásicos con protagonistas femeninos que construye Mistral, he expuesto la americanización que elabora Mistral y su visión crítica respecto de la situación de la mujer latinoamericana a inicios del siglo XX. Mistral revela su conciencia adelantada respecto de los derechos de las niñas y niños desde una ética del cuidado, a través de la cual mira y critica a la sociedad latinoamericana del 1920. Mistral celebra la agencia de las niñas. Sus protagonistas escapan a los estereotipos burgueses centroeuropeos, ofreciendo modelos de género alternativos y pertinentes para el contexto cultural de sus lectoras: hadas con morrales campesinos, Marías trabajadoras, niñas independientes que vuelan a través de montañas y bosques con el fin de encontrar su propio camino a casa, abriendo paso para que sus lectoras se inspiren y confíen que pueden elegir su propio camino. 
Desde la oralidad expresada en los versos octosilábicos y alejandrinos, a los comentarios metanarrativos, conexiones con otros cuentos de hadas, intertextos culturales, bíblicos y literarios, los versos de Mistral pueden ser leídos en diversos niveles, ofreciendo espacio para interpretaciones y asociaciones posteriores a su escritura como nuevas capas de compostaje cultural, estableciendo diálogos con nuevas lecturas de los hermanos Grimm y Perrault e incluso versiones cinematográficas posteriores que parecen más conservadoras y abusivas que los versos de Mistral. En este sentido, las ilustraciones de las publicaciones aquí analizadas lamentablemente descansan en la iconografía europea (salvo quizás por el cabello oscuro de Cenicienta y Bella Durmiente), particularmente en tanto los atuendos de las niñas, ignorando la americanización que figura en Mistral. Destaco, no obstante, que de las cuatro publicaciones a cargo de Amanuta, la propuesta estética de Cardemil, por el uso de las técnicas del collage y grattage, expande la cualidad de compostaje cultural que observamos en los versos mistralianos en tanto el collage reúne fragmentos diversos, aportando una variedad de texturas en coherencia con la escritura basada en referentes anteriores, a la vez que el gesto de quitar y develar del grattage invita a sus lectoras a rasguñar la superficie para revelar los significados profundos que Mistral nos presenta.

\section{Referencias bibliográficas}

Curtin, Deane. "Toward an ecological ethic of care". Hypatia, vol. 6, no. 1, pp. 60-74.

Dudek, Debra. "Seeing the human face: Refugee and asylum seeker narratives and an ethics of care in recent Australian picture books". Children's Literature Association Quarterly, vol. 43, no. 4, pp. 363-376.

Falabella, Soledad. "Infancia y autobiografía en Gabriela Mistral: problematización de clase, género y etnia en el Poema de Chile". Gabriela Mistral, Estudios Universidad de Chile, 2020. Recuperado de http://www.gabrielamistral.uchile.cl/estudiosframe.html

Figueroa, Lorena, Keiko Silva y Patricia Vargas. Tierra, indio, mujer: pensamiento social de Gabriela Mistral. Santiago de Chile, LOM ediciones y Universidad Arcis, 2000. Recuperado de http://www.cervantesvirtual.com/ 
Gilligan, Carol. "Interview". Ethics of care, junio 2011, s/n. Recuperado de https://ethicsofcare.org/carol-gilligan/

Mayne-Nicholls, Alida. "Espacios tomados: Representación de niñas en Gabriela Mistral y María Flora Yáñez". Tesis. Pontificia Universidad Católica de Chile, 2019.

"Mistral ilustrada: un desvío en el camino". Cuadernos Intermediales, vol. 1. Eds. Franken, M. Angélica y Mary MacMillan. Santiago de Chile, Cuarto Propio, 2020 (en prensa).

Ministerio de Desarrollo Social y Familia. Encuesta Casen 2017. Recuperado de http://observatorio.ministeriodesarrollosocial. gob.cl/

Mistral, Gabriela. "Algunos rasgos de la geografía humana de Chile". Gabriela Mistral: Caminando se siembre. Prosa inédita. Comp. Luis Vargas Saavedra. Santiago de Chile, Lumen, 2013, pp. 29-49.

"Andersen". Almácigo; poemas inéditos. Comp. Luis Vargas Saavedra. Santiago de Chile, Ediciones UC, 2015, p. 328.

Blanca Nieve en la casa de los enanos. Ilustraciones de Carles Ballesteros. Santiago de Chile, Amanuta, 2014.

Caperucita Roja. Ilustraciones de Paloma Valdivia. Santiago de Chile, Amanuta, 2014.

"Cordillera II". Almácigo; poemas inéditos. Comp. Luis Vargas Saavedra. Santiago de Chile: Ediciones UC, 2015, p. 45.

"Introducción". Lecturas para mujeres. Comp. Gabriela Mistral. México, D.F., s/editorial, 1924, pp. 7-17. Recuperado de http://www.memoriachilena.gob.cl/archivos2/pdfs/ MC0003267.pdf

La Bella Durmiente del Bosque. Ilustraciones de Carmen Cardemil. Santiago de Chile, Amanuta, 2012.

La Cenicienta. Ilustraciones de Bernardita Ojeda. Santiago de Chile, Amanuta, 2014.

"La madre triste". Gabriela Mistral en verso y poesía. Ed. Real Academia Española y Asociación de Academias de la Lengua Española. Madrid, Alfaguara, 2010, p. 105.

Los motivos de San Francisco. Santiago de Chile, Ed. Andrés Bello, 2008.

. Magisterio y niño. Comp. Roque Esteban Scarpa. Santiago de Chile, Ed. Andrés Bello, 1979, pp. 62-65. Recuperado 
de http://www.memoriachilena.gob.cl/archivos2/pdfs/ MC0010808.pdf

"Pan". Gabriela Mistral en verso y poesía. Ed. Real Academia Española y Asociación de Academias de la Lengua Española. Madrid, Alfaguara, 2010, pp. 225-226.

"Piececitos". Gabriela Mistral en verso y poesía. Ed. Real Academia Española y Asociación de Academias de la Lengua Española. Madrid, Alfaguara, 2010, pp. 177-178.

"Sol del trópico". Gabriela Mistral en verso y poesía. Ed. Real Academia Española y Asociación de Academias de la Lengua Española. Madrid, Alfaguara, 2010, pp. 263-276.

Noddings, Nel. "The Language of Care Ethics". Knowledge Quest: Journal of the American Association of Scholl Librarians. vol. 40, no. 4, pp. 52-56.

Peña, Manuel. "Blanca Nieve en la casa de los enanos: una versión original". Gabriela Mistral. Blanca Nieve en la casa de los enanos. Ilustraciones de Carles Ballesteros. Santiago de Chile, Amanuta, 2014, pp. 30-31.

Pérez López, María Ángeles. "La autotextualidad en Nicanor Parra: Acotar/Agotar/Reciclar." Anales de Literatura Chilena, no. 4, 2003, pp. 165-175.

Perrault, Charles. Cuentos de hadas. Ilustraciones de Doré. Barcelona, Lumen, 1993.

Rojo, Grínor. Dirán que está en la gloria. México, D.F., Fondo de Cultura Económica, 1997.

Salazar, Gabriel V. Ser niño "huacho" en la historia de Chile (siglo XIX). Santiago de Chile, LOM ediciones, 2006.

Sepúlveda, Magda. Gabriela Mistral: Somos los andinos que fuimos. Santiago de Chile, Cuarto Propio, 2018.

Yosoyoho. Marías. Documental publicado en Facebook, 2017. Recuperado de https://www.facebook.com/ watch/?v=860117457496417

Zipes, Jack. "The Rationalization of Abandonment and Abuse in Fairy Tales". Happily Ever After: Fairy Tales, Children and the Culture Industry. New York, Routledge, 1997. pp.39-60. 